\title{
MORFOLOGIA FOLIAR DE SORGO SACARINO CULTIVADO EM DIFERENTES ESPAÇAMENTOS ENTRELINHAS E ÉPOCAS DE SEMEADURA
}

\author{
ANDRIÉLI HEDLUND BANDEIRA ${ }^{1}$, SANDRO LUIS PETTER MEDEIROS ${ }^{2}$, \\ BEATRIZ MARTI EMYGDIO³, JEAN CECCHIM BIONDO² e LINEU TRINDADE LEAL 2
}

\begin{abstract}
Instituto Federal Farroupilha-IF Farroupilha - Campus Alegrete, Alegrete-RS, Brasil andrieli_hedlund@hotmail.com ${ }^{2}$ Universidade Federal de Santa Mari-UFSM, Departamento de Fitotecnia e Departamento de Solos, Santa Maria-RS, Brasil slpmedeiros@yahoo.com.br,jeanbiondo@hotmail.comelineuleal@yahoo.com.br

${ }^{3}$ Embrapa Clima Temperado,Pelotas-RS,Brasil beatriz.emygdio@embrapa.br
\end{abstract}

Revista Brasileira de Milho e Sorgo, v.17, n.1, p. 63-75, 2018

\begin{abstract}
RESUMO - O objetivo deste trabalho foi avaliar as características morfogênicas do colmo principal de genótipos de sorgo sacarino, em diferentes espaçamentos entrelinhas e épocas de semeadura. O experimento foi conduzido em Santa Maria-RS, em delineamento experimental de blocos ao acaso em esquema trifatorial (2x2x3), com dois genótipos de sorgo sacarino (BRS 506 e Fepagro 19), dois espaçamentos entrelinhas (0,50 m e 0,70 m) e três épocas de semeadura (outubro, novembro e dezembro), quatro repetições e dois anos de cultivo. Foram avaliadas a taxa de alongamento das folhas, o número final de folhas no colmo, a taxa de surgimento de folha, filocrono e taxa de elongamento de colmo. As variáveis não apresentaram interação tripla significativa entre genótipo, espaçamento de entrelinhas e época de semeadura. O genótipo BRS 506 apresentou número de folhas acumuladas, taxa de alongamento de folhas nas épocas de semeaduras constante. $\mathrm{O}$ atraso na época de semeadura resulta em menor número de folhas acumuladas e taxa de elongação do colmo para o Fepagro 19. O filocrono para o espaçamento entrelinhas $0,70 \mathrm{~m}$ é inferior ao de 0,50 m. Os genótipos estudados estão aptos para a produção na região, desde que a semeadura ocorra no mês de outubro.
\end{abstract}

Palavras-chave: alongamento foliar, filocrono, graus-dia, índice Haun, Sorghum bicolor.

\section{LEAF MORPHOLOGY OF SWEET SORGHUM CULTIVATED IN DIFFERENT ROW SPACINGS AND SOWING DATES}

\begin{abstract}
The objective of this work was to evaluate the morphogenic characteristics of the main stem of sweet sorghum genotypes in different spacing between lines and sowing times. The experimental was carried out in a randomized complete block design in a trifactorial scheme $(2 \times 2 \times 3)$, with two sweet sorghum (BRS 506 and Fepagro 19), two spacing between lines $(0.50 \mathrm{~m}$ and $0.70 \mathrm{~m})$ and three sowing seasons (October, November and December), four replications and two years of cultivation. The leaf elongation rate, the final number of leaves in the stem, the leaf appearance rate, phyllochron and shoot elongation rate were evaluated. The variables did not present significant triple interaction between genotype, spacing between rows and sowing time. The genotype BRS 506 presented a number of accumulated leaves, leaf elongation rate at constant sowing times. The delay in sowing seasons results in a lower number of accumulated leaves and the elongation rate of the stem for genotype Fepagro 19. The phyllochron for the $0.70 \mathrm{~m}$ line spacing is less than $0.50 \mathrm{~m}$. The genotypes studied are suitable for production in the region, as long as sowing occurs in October.
\end{abstract}

Keywords: leaf elongation, phyllochron, degree-days, Haun index, Sorghum bicolor. 
O sorgo (Sorghum bicolor L. Moench) é uma cultura que possui grande importância, por ser de fácil manejo cultural e fonte de alimentação animal de baixo custo, entre outros usos. Atualmente, vem se destacando como uma cultura promissora para a produção de etanol, fornecendo matéria-prima para as usinas na entressafra da cana-de-açúcar. No Estado do Rio Grande do Sul, a pesquisa com o sorgo sacarino é escassa, principalmente no que tange a informações a respeito do crescimento e desenvolvimento de genótipos, com base nas variáveis morfogênicas, sendo que essas são consideradas ferramentas adicionais na escolha do manejo mais adequado da cultura, além de ser utilizadas como critério de seleção em programas de melhoramento genético (Müller, 2009).

A utilização das variáveis morfogênicas como critério na seleção de genótipos é essencial, pois as respostas de adaptabilidade e estabilidade dos materiais selecionados estão considerando as influências das variáveis meteorológicas e não apenas a produtividade de uma maneira isolada. Conforme Townsend (2008) e Müller (2009), a morfogênese conceitua-se como a dinâmica de geração e expansão da forma da planta no espaço, estando esta dinâmica relacionada às constantes oscilações do ambiente. Portanto, deve ser analisada cuidadosamente a fim de entender as formas pelas quais as plantas respondem a variações ambientais, pois inclui a taxa de surgimento de novos órgãos, suas taxas de expansão, de senescência e decomposição. Sendo que essas variáveis estão relacionadas diretamente à produtividade da cultura.

Para utilizar-se das variáveis morfogênicas, a temperatura do ar deve ser considerada, pois ela interfere diretamente nos processos fisiológicos da cultura do sorgo, o que acaba afetando cada subperíodo do seu desenvolvimento. Além disto, as plantas possuem uma temperatura mínima, na qual abaixo dela ocorre cessamento das atividades fisiológicas, interferindo diretamente no seu crescimento e desenvolvimento (Martins et al., 2007). Entre as interferências causadas pela temperatura do ar inclui-se a taxa de emissão de folhas. Assim, a medida ou estimativa da emissão de folhas é importante, pois se integrando à taxa de emissão de folhas tem-se o número de folhas acumulado na haste, que é uma ferramenta que estima a idade fisiológica da planta. Inclusive o número de folhas está associado à área foliar da planta, responsável pela interceptação da radiação solar pelo dossel para utilização na fotossíntese (Hanauer et al., 2014).

Para estimar a emissão de folhas em uma cultura, utiliza-se a técnica dos perfilhos marcados, e posteriormente utiliza-se o conceito do filocrono. Segundo McMaster e Wilhelm (1995) e Rosa et al. (2009), o filocrono pode ser definido como o intervalo de tempo entre a emissão de duas folhas sucessivas sobre o primórdio vegetativo no intervalo entre estágios similares de desenvolvimento de folhas. Frequentemente utiliza-se para representar o tempo fisiológico em plantas o conceito da soma térmica ou dos grausdia, onde são acumulados os valores de temperatura média diária do ar acima de uma temperatura base inferior, considerada a temperatura abaixo da qual não ocorre desenvolvimento ou este é tão lento que pode ser considerado desprezível, ou seja, o filocrono é o acúmulo térmico necessário para o aparecimento de uma folha (McMaster \& Wilhelm, 1997).

A fim de obter recomendações técnicas mais precisas para a cultura do sorgo sacarino, deve-se atrelar as variáveis morfogênicas com manejos culturais diferenciados, ou seja, estudar diferentes épocas de semeadura e espaçamento entrelinhas torna as recomendações técnicas ao produtor mais seguras e precisas. A época de semeadura correta é importante na busca de altas produtividades, pois a semeadura 
em uma época inapropriada confere à cultura a ocorrência de adversidades meteorológicas durante fases importantes de crescimento e desenvolvimento, podendo levar ao risco de insucesso na exploração da cultura. De maneira geral, as Indicações Técnicas para a Cultura do Sorgo da Embrapa recomendam o espaçamento para a semeadura de sorgo de $0,70 \mathrm{~m}$ entrelinhas. No entanto, autores como Albuquerque et al. (2010) e Fernandes et al. (2014) relatam que o reduzido espaçamento entrelinhas favorece o crescimento e o desenvolvimento da cultura, em razão do aumento na eficiência da utilização de luz, água, nutrientes e controle de plantas daninhas.

Poucos são os trabalhos na cultura do sorgo sacarino que mostram a importância das variáveis morfogênicas como ferramenta auxiliar na tomada de decisão no planejamento do sistema de produção da propriedade, principalmente nas condições edafoclimáticas da Depressão Central do Rio Grande do Sul. Logo, pesquisas que considerem a morfogênese associada a experimentos com diferentes épocas de semeadura e espaçamento entrelinhas são importantes em estudos de crescimento e desenvolvimento das plantas. Neste sentido, o objetivo do trabalho foi avaliar as variáveis morfogênicas no colmo principal, de dois genótipos de sorgo sacarino (BRS 506 e Fepagro 19), sob dois espaçamentos de entrelinhas, cultivados em diferentes épocas de semeadura.

\section{Material e Métodos}

O experimento foi realizado na Universidade Federal de Santa Maria, localizada no município de Santa Maria, na Depressão Central do Rio Grande do Sul, com altitude média de $95 \mathrm{~m}$ e coordenadas de $29^{\circ} 43^{\prime} \mathrm{S}$ e $53^{\circ} 43^{\prime} \mathrm{W}$. O clima da região é o Cfa (subtropical úmido com verões quentes e sem estação seca definida), conforme classificação de Köppen. Os dados da temperatura do ar e precipitação foram obtidos na Estação Climatológica Principal da UFSM, pertencente ao $8^{\circ}$ DISME/INMET/MA, localizada a $600 \mathrm{~m}$ da área experimental (Figuras 1 e 2).

O delineamento experimental utilizado foi blocos ao acaso, com tratamentos distribuídos em esquema fatorial $(2 \times 2 \times 3)$, com dois espaçamentos entrelinhas, dois genótipos e três épocas de semeaduras, com quatro blocos. Os espaçamentos entrelinhas testados foram de $0,50 \mathrm{~m}$ e $0,70 \mathrm{~m}$; já os genótipos de sorgo sacarino utilizados foram BRS 506 e Fepagro 19, sendo ambas as variedades oriundas dos programas de melhoramento da Fepagro-RS e Embrapa Milho e Sorgo. As datas de semeadura foram: 04/10, 15/11 e 17/12/2011 (ano I) e 24/10, 28/10 e 14/12/2012 (ano II), correspondendo a dois anos agrícolas, a fim de minimizar o efeito do ambiente, para fins de recomendação de genótipo e época de semeadura.

O solo do local pertence à Unidade de Mapeamento Santa Maria (Argissolo Bruno-Acinzentado). A correção do $\mathrm{pH}$ e a adubação do solo foram realizadas seguindo as recomendações da Comissão de Química e Fertilidade do Solo - RS/SC (Manual..., 2016), a partir de análise de solo da área experimental, que apresentava valores de $\mathrm{pH}$ em água de 5,$4 ; 5,5 \mathrm{cmol}_{\mathrm{c}}$ $\mathrm{dm}^{-3}$ de $\mathrm{H}+\mathrm{Al} ; 0,2 \mathrm{cmol}_{\mathrm{c}} \mathrm{dm}^{-3}$ de Al; 4,8 $\mathrm{cmol}_{\mathrm{c}} \mathrm{dm}^{-3}$ de Ca; 2,6 $\mathrm{cmol}_{\mathrm{c}} \mathrm{dm}^{-3}$ de $\mathrm{Mg} ; 0,082 \mathrm{cmol}_{\mathrm{c}} \mathrm{dm}^{-3} \mathrm{de} \mathrm{K}$; $76,0 \mathrm{mg} \mathrm{dm}^{-3}$ de P-Mehlich; 1,8\% de MO e 20,0\% de argila. Em 10 de agosto de 2011, foram aplicadas 5,2 $\mathrm{t} \mathrm{ha}^{-1}$ de calcário (PRNT 75,4\%). Com base na análise de solo, a adubação de base indicada foi de $20 \mathrm{~kg}$ ha-1 de nitrogênio $(\mathrm{N})$ e 120 e $175 \mathrm{~kg} \mathrm{ha}^{-1}$ de potássio (K) no ano I e ano II, respectivamente; para ambos os anos, não foi necessária a utilização de fósforo $(\mathrm{P})$ (considerado muito alto, conforme Manual de adubação e calagem para os estados do Rio Grande do 
Sul e de Santa Catarina). A adubação nitrogenada em cobertura foi parcelada em duas aplicações (perfilhamento e alongamento), totalizando $50 \mathrm{~kg} \mathrm{ha}^{-1} \mathrm{de} \mathrm{N}$, na forma de ureia $(45,0 \%$ de $\mathrm{N})$. O solo foi preparado pelo método convencional, e a semeadura foi feita manualmente, em linhas, sendo que a unidade experimental foi composta de cinco linhas espaçadas em $0,50 \mathrm{~m}$ e $0,70 \mathrm{~m}$, com $5 \mathrm{~m}$ de comprimento, na população inicial de 120.000 plantas por hectare. Este valor foi corrigido de acordo com a pureza e a germinação.

Após a emergência, foram escolhidas aleatoriamente três linhas por parcela com três plantas marcadas, que foram identificadas com arames coloridos. Com o auxílio de uma régua milímetrada foram efetuadas medições do comprimento das folhas: comprimento da última folha em expansão (quando a lígula ainda não estava exposta) e comprimento da folha completamente expandida (após o aparecimento da lígula) do colmo principal, semanalmente, desde a emergência até o aparecimento da folha bandeira, e foi contado o número final de folhas por colmo.

Posteriormente, calcularam-se as seguintes variáveis: número final de folhas, somatório de folhas do colmo, da emergência até a emissão da folha bandeira; taxa de surgimento de folhas, obtida pela divisão do número de folhas completamente expandidas (lígula exposta) surgidas por perfilho pela soma térmica do período, expressa em folhas ${ }^{\circ} \mathrm{C}$ dia $^{-1}$; filocrono: intervalo de tempo térmico entre o aparecimento de duas folhas sucessivas, calculado por intermédio da regressão entre o índice de Haun e o acúmulo de graus-dia, expresso em ${ }^{\circ} \mathrm{C}$ dia folha ${ }^{-1}$.

A estimativa dos graus-dia (GD), ${ }^{\circ} \mathrm{C}$ dia, acumulados durante um dia foi obtida pela seguinte fórmula, se: $\mathrm{Tb} \leq \mathrm{Tmin}$, conforme Schneider et al. (1987): $\mathrm{GD}=(1 / 5)[\mathrm{T} 9 \mathrm{~h}+\mathrm{Tmax}+\mathrm{Tmin}+(2 \mathrm{~T} 21 \mathrm{~h})]-\mathrm{Tb}$; se: $\mathrm{Tb}>\mathrm{Tmin}$, conforme Villa Nova et al. (1999): GD =
$(T \max -\mathrm{Tb})^{2} /[2(\mathrm{Tmax}-\mathrm{Tmin})]$. Em que: GD= graus-dia; T9h e T21h são as temperaturas às $9 \mathrm{~h}$ e $21 \mathrm{~h}$, respectivamente; Tmax e Tmin são as temperaturas máxima e mínima do ar, respectivamente; e Tb é a temperatura base do subperíodo vegetativo, definida como a temperatura mínima abaixo da qual não há emissão de folhas.

A soma térmica acumulada ( $\mathrm{STa}),{ }^{\circ} \mathrm{C}$ dia, de cada genótipo foi obtida pelo somatório dos graus-dia acumulados durante os dias necessários para completar o subperíodo vegetativo: $\mathrm{STa}=\sum \mathrm{GD}$. As temperaturas bases inferiores adotadas foram de $11,6{ }^{\circ} \mathrm{C}$ para o genótipo de sorgo sacarino Fepagro 19 e de $11,8^{\circ} \mathrm{C}$ para o genótipo BRS 506 (Bandeira et al., 2016).

Os anos agrícolas não são um fator em estudo, por isso, foram utilizados na análise conjunta, a fim de minimizar a interferência nos dados das variáveis meteorológicas (temperatura do ar, precipitação, umidade, incidência de radiação, entre outras), que variam entre os anos, e assim garantir maior segurança na recomendação local da semeadura de um determinado genótipo, pois é necessário conhecer e validar o seu comportamento e seu desempenho agronômico, quando expostas às variáveis de clima de um determinado local. Logo, é preciso que diferentes genótipos sejam avaliados em no mínimo dois ambientes, pois a avaliação em apenas um ambiente não permite confiabilidade nos resultados, ocasionando erros nas estimativas da variância genética, e, consequentemente, nas estimativas da herdabilidade, sujeitando a erro também o ganho com a seleção (Molina, 2007).

Os dados obtidos foram submetidos à análise da variância. Quando significativas, as médias foram comparadas entre si pelo Teste de Tukey, com nível de $5 \%$ de probabilidade de erro, utilizando o programa estatístico Assistat, versão beta 7.7 (Silva \& Azevedo, 2016). 


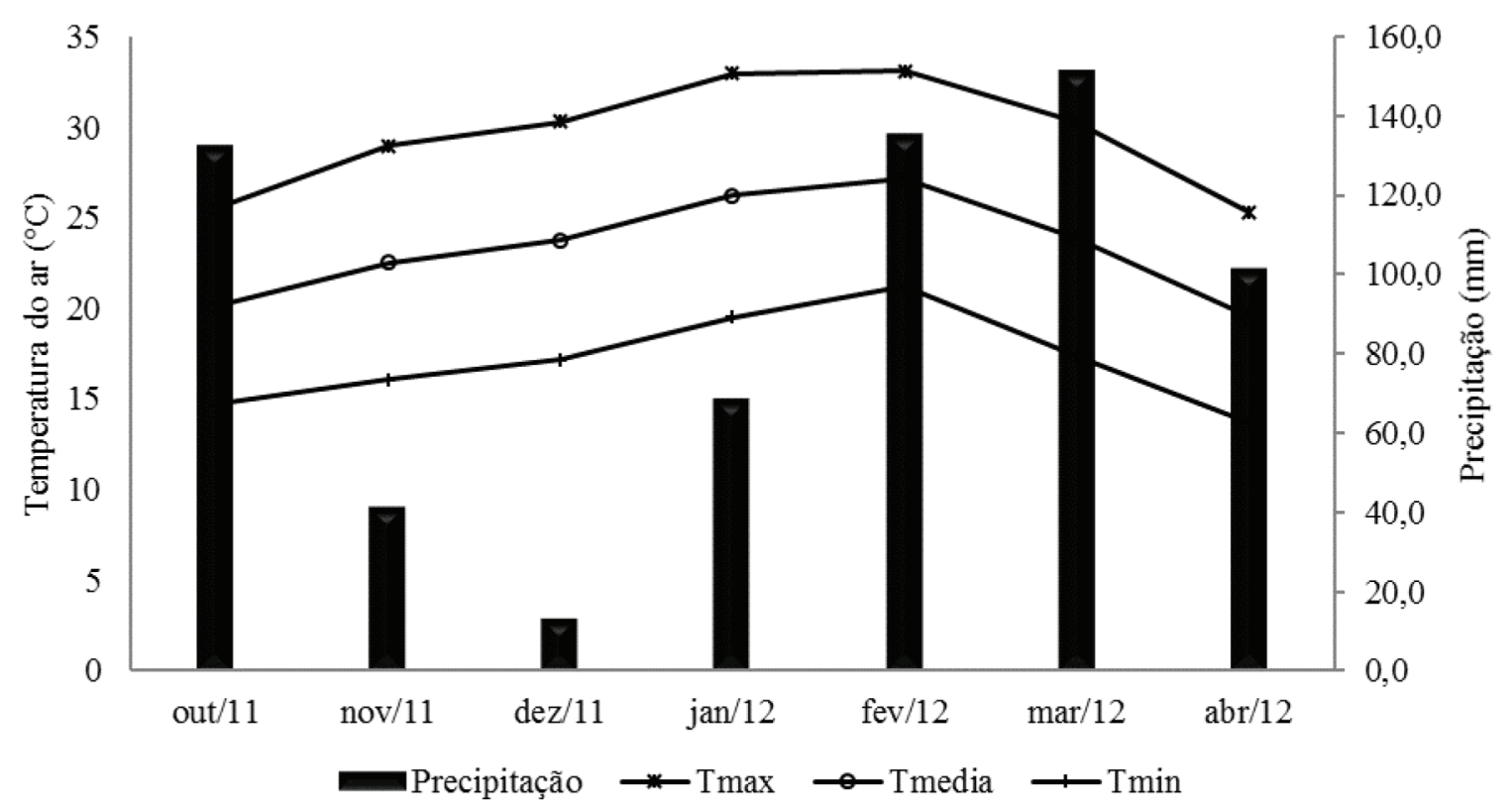

Figura 1 - Valores mensais de precipitação e da temperatura mínima (Tmin), temperatura média (Tmed) e temperatura máxima do ar (Tmax), de outubro de 2011 a abril de 2012.

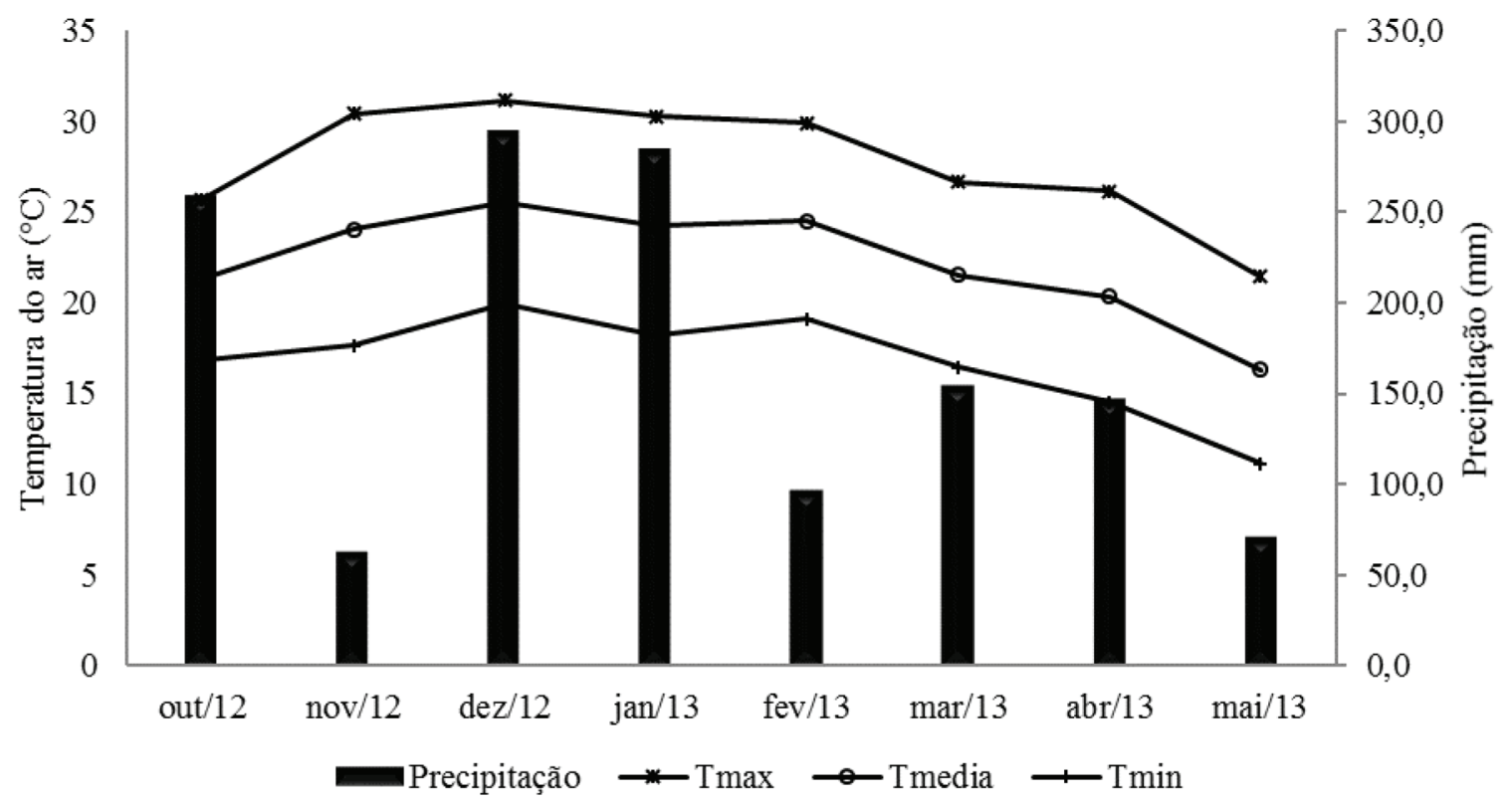

Figura 2 - Valores mensais de precipitação e da temperatura mínima (Tmin), temperatura média (Tmed) e temperatura máxima do ar (Tmax), de outubro de 2012 a maio de 2013. 


\section{Resultados e Discussão}

A análise de variância para taxa de surgimento de folhas (TSF), taxa de alongamento de folhas (TAF), taxa de elongamento de colmo (TEC), número de folhas acumuladas (NFA) e filocrono (FILO) não apresentou interação tripla significativa entre genótipos, espaçamento entrelinhas e época de semeadura. Porém, houve significância para as interações entre espaçamento entrelinhas $\mathrm{x}$ épocas de semeaduras e genótipos $\mathrm{x}$ época de semeadura (Tabela 1). Essa resposta evidencia a importância de pesquisas que avaliem o crescimento e desenvolvimento de folhas e colmo no sorgo sacarino em diferentes épocas de semeaduras.

As interações duplas entre os fatores genótipos e épocas de semeaduras foram significativas $(p<0,05)$ para as variáveis: taxa de alongamento de folhas (TAF), taxa de surgimento de folhas (TSF) e número de folhas acumuladas (NFA) (Tabela 1).

A taxa de alongamento foliar não apresentou diferença significativa entre as épocas de semeaduras para os dois genótipos estudados (Tabela 2), ou seja, essa variável não sofreu interferência da época de semeadura. Na semeadura realizada no mês de dezembro, o genótipo BRS 506 foi superior em 12,25 mm
${ }^{\circ} \mathrm{C}$ dia $^{-1}$, em relação ao genótipo Fepagro 19 (Tabela 2). A taxa de alongamento foliar (TAF) é uma variável que, quando apresenta diferenças entre os genótipos, pode acarretar práticas de manejos diferenciadas entre os materiais, principalmente quando o foco do manejo for a produção de forragem e/ou duplo propósito (forragem/etanol) de melhor qualidade. Segundo Horst et al. (1977), a fração de folha influencia positivamente a eficiência de pastejo e o valor nutricional da forragem produzida, além de ser considerada, entre as variáveis morfogênicas, a que mais se correlaciona com a massa seca de forragem.

A taxa de surgimento de folhas para o genótipo BRS 506 na semeadura de dezembro foi maior, diferindo significativamente das demais épocas de semeaduras (Tabela 2). Já para o genótipo Fepagro 19, a semeadura do mês de novembro apresentou a menor taxa de surgimento de folhas (Tabela 2). Na semeadura do mês de novembro, os genótipos não apresentaram diferença entre si quanto a TSF; já para a semeadura de outubro o genótipo Fepagro 19 apresentou maior TSF em comparação ao BRS 506 (Tabela 2). A taxa de surgimento foliar, segundo Lemaire e Chapmam (1996), pode ser considerada a característica principal da morfogênese em razão da sua influência sobre os três componentes principais da estrutura do

Tabela 1 - Grau de significância $(\operatorname{Pr}<\mathrm{F})$ da análise de variância para as variáveis taxa de surgimento de folhas (TSF), taxa de alongamento de folhas (TAF), taxa de elongamento de colmo (TEC), número de folhas acumuladas (NFA) e filocrono (FILO) para genótipos de sorgo sacarino, espaçamento de entrelinhas e épocas de semeaduras.

\begin{tabular}{llllll}
\hline Causa de variação & TAF & TSF & NFA & TEC & FILO \\
\hline Genótipo & $>0,050$ & $>0,050$ & $>0,050$ & $>0,050$ & $>0,050$ \\
Espaçamento entrelinhas & $<0,050$ & $>0,050$ & $>0,050$ & $>0,050$ & $<0,050$ \\
Épocas de semeadura & $>0,050$ & $<0,050$ & $<0,050$ & $<0,050$ & $<0,050$ \\
Genótipo x espaçamento & $>0,050$ & $>0,050$ & $>0,005$ & $>0,050$ & $>0,050$ \\
Genótipo x épocas & $<0,050$ & $<0,050$ & $<0,050$ & $>0,050$ & $>0,050$ \\
Espaçamento x épocas & $>0,050$ & $<0,050$ & $>0,050$ & $<0,050$ & $<0,050$ \\
Gen. x Esp. x Épocas & $>0,050$ & $>0,050$ & $>0,050$ & $>0,050$ & $>0,050$ \\
\hline
\end{tabular}


dossel: comprimento final da folha, densidade populacional de perfilhos e números de folhas determinando o índice de área foliar da planta.

A TSF é afetada de forma diferenciada pelo corte ou pastejo, de forma marcante pela temperatura e pelo suprimento de nitrogênio (Sales et al., 2014). Diversos autores relatam que a taxa de surgimento de folhas possui correlação negativa com o alongamento de folhas (TAF) de forma que quanto maior a TSF, menor o alongamento das folhas, no entanto, essa resposta não foi evidenciada no presente estudo (Pena et al., 2009; Sales et al., 2014).

Observou-se diferença significativa entre os genótipos apenas na semeadura no mês de outubro, sendo que o genótipo Fepagro 19 foi superior em duas folhas em relação ao BRS 506. O genótipo Fepagro 19 sofreu interferência no número de folhas acumuladas no colmo com avanço da época de semeadura (Tabela 2). Já para o genótipo BRS 506 a semeadura do mês de novembro apresentou o menor número de folhas acumuladas. Streck et al. (2006) relatam que para alguns genótipos há efeito da época de semeadura, sendo que semeaduras realizadas no cedo apresentam maior número final de folhas e semeaduras tardias apresentam um menor número de folhas acumuladas no colmo.

Não houve interação significativa $(p>0,05)$ entre genótipos e épocas de semeaduras para o filocrono e taxa de elongamento de colmo (Tabela 1). Os genótipos não apresentaram diferença significativa entre si para taxa de elongamento do colmo e filocrono (Tabela 2). Lemaire e Agnusdei (2000) relatam que dentro de uma mesma espécie o filocrono é uma variável relativamente constante, principalmente quando expresso em tempo térmico, o que promove uma base de escala para o estudo da morfogênese. Santos (2004) e Müller (2009), avaliando diferentes genótipos de azevém, não encontraram diferenças para o filocrono entre os materiais avaliados, e Streck et al. (2006), avaliando arroz, encontraram resultado semelhante ao desse estudo. Relatam também que as diferenças genotípicas são mínimas e podem ser desconsideradas, enquanto o ambiente, principalmente pela época de semeadura, tem grande influência no filocrono.

A semeadura no mês de outubro proporcionou uma maior taxa de elongamento de colmo, diferindo significativamente das demais épocas de semeaduras (Tabela 2). Isso pode ter sido causado pela temperatura do ar no período (Figura 1 e Figura 2), favorecendo um maior número de folhas e uma maior taxa de surgimento de folhas. A maior taxa de elongamento de colmo pode resultar em plantas de colmos mais altos, portanto, mais produtivos. Visando a produção de etanol, colmos mais altos tendem a garantir maior produtividade. Se essa produtividade for acompanhada de alto teor de brix e fibra em torno de $13 \%$, a semeadura do mês de outubro tende a ser a mais indicada para atender a produção de etanol.

Houve significância na interação dupla entre espaçamento entrelinhas e épocas de semeaduras para a taxa de elongamento do colmo (TEC), filocrono (FIL) e taxa de surgimento de folhas (TSF) (Tabela 1). O espaçamento entrelinhas diferiu entre si apenas na semeadura realizada no mês de novembro, sendo que o espaçamento de entrelinhas de $0,50 \mathrm{~m}$ apresentou o maior filocrono $(\mathrm{p}<0,05)$ em relação ao espaçamento de 0,70 m nas entrelinhas. Além disso, a semeadura realizada em novembro proporcionou o maior filocrono (Tabela 3).

A taxa de surgimento de folhas apresentou diferença significativa entre os espaçamentos entrelinhas $(\mathrm{p}<0,05)$ apenas na semeadura do mês de novembro (Tabela 3). Para ambos os espaçamentos entrelinha a maior taxa de surgimento de folhas foi na semeadura 
Tabela 2 - Taxa de alongamento de folhas (TAF); taxa de surgimento de folhas (TSF), número de folhas acumuladas (NFA), filocrono (FIL) e taxa de elongamento de colmo (TEC) de genótipos de sorgo sacarino submetido a diferentes épocas de semeaduras.

\begin{tabular}{|c|c|c|c|c|}
\hline \multirow{2}{*}{ Tratamentos } & Outubro & Novembro & Dezembro & Média \\
\hline & \multicolumn{4}{|c|}{ Taxa de alongamento de folhas $\mathrm{mm}\left({ }^{\circ} \mathrm{C} \mathrm{dia}\right)^{-1}$} \\
\hline BRS 506 & $72,79 \mathrm{Aa}$ & $83,12 \mathrm{Aa}$ & $83,62 \mathrm{Aa}$ & -- \\
\hline Fepagro 19 & $82,54 \mathrm{Aa}$ & 77,96 Аa & 71,37 Ba & -- \\
\hline \multirow[t]{2}{*}{$\mathrm{CV}(\%)$} & & 23,17 & & \\
\hline & \multicolumn{4}{|c|}{ Taxa de surgimento de folhas folhas $\left({ }^{\circ} \mathrm{C} \text { dia }\right)^{-1}$} \\
\hline BRS 506 & $0,0214 \mathrm{Bb}^{*}$ & $0,0190 \mathrm{Ac}$ & $0,0250 \mathrm{Aa}$ & -- \\
\hline Fepagro 19 & $0,0230 \mathrm{Aa}^{*}$ & $0,0195 \mathrm{Ab}$ & $0,0227 \mathrm{Ba}$ & -- \\
\hline \multirow[t]{2}{*}{$\mathrm{CV}(\%)$} & & 10,77 & & \\
\hline & \multicolumn{4}{|c|}{ Número folhas acumulados } \\
\hline BRS 506 & $22,00 \mathrm{Ba}^{*}$ & $20,00 \mathrm{Ab}$ & $22,00 \mathrm{Aa}$ & -- \\
\hline Fepagro 19 & $24,00 \mathrm{Aa}$ & $21,00 \mathrm{Ab}$ & $21,00 \mathrm{Ab}$ & -- \\
\hline \multirow[t]{2}{*}{$\mathrm{CV}(\%)$} & & 7,59 & & \\
\hline & \multicolumn{4}{|c|}{ Filocrono ${ }^{\circ} \mathrm{C}$ dia folha ${ }^{-1}$} \\
\hline BRS 506 & 50,93 & 59,26 & 46,69 & $52,29 \mathrm{~A}^{*}$ \\
\hline Fepagro 19 & 50,34 & 57,37 & 47,83 & $51,84 \mathrm{~A}$ \\
\hline Média & $50,63 b^{*}$ & $58,31 \mathrm{a}$ & $47,26 \mathrm{c}$ & -- \\
\hline \multirow[t]{2}{*}{$\mathrm{CV}(\%)$} & & 12,52 & & \\
\hline & \multicolumn{4}{|c|}{ Taxa de elongamento do colmo $\mathrm{cm}\left({ }^{\circ} \mathrm{C} \mathrm{dia}\right)^{-1}$} \\
\hline BRS 506 & 29,08 & 25,33 & 22,91 & $25,77 \mathrm{~A}^{*}$ \\
\hline Fepagro 19 & 26,37 & 24,62 & 23,54 & $24,84 \mathrm{~A}$ \\
\hline Média & $27,73 \mathrm{a}^{*}$ & $24,98 \mathrm{~b}$ & $23,23 b$ & -- \\
\hline $\mathrm{CV}(\%)$ & & 22,43 & & \\
\hline
\end{tabular}

*Médias seguidas da mesma letra maiúscula na coluna e minúscula na linha não diferem significativamente entre si pelo teste Tukey a $5 \%$ de significância. CV $(\%)=$ coeficiente de variação em percentagem.

do mês de dezembro (Tabela 3). Essa resposta pode ser atribuída às temperaturas do ar às quais as plantas da semeadura em dezembro estavam submetidas no auge do seu subperíodo vegetativo, já que a partir do mês de fevereiro houve um decréscimo das temperaturas do ar (temperatura base inferior do sorgo sacarino muito próximo da temperatura média do ar). Com isso, há menor acúmulo térmico diário, consequentemente, maior o período para o surgimento de folhas no colmo (Figura 1 e Figura 2). Essa é uma característica de extrema importância para a planta, uma vez que a lâmina foliar é a responsável pela interceptação de luz, além de ser a variável que norteia a morfogênese das poáceas (Martini, 2015).
A taxa de elongamento do colmo no mês de outubro proporcionou no espaçamento $0,50 \mathrm{~m}$ de entrelinhas a maior taxa de elongação, diferindo significativamente das demais épocas. Em contrapartida, ela não foi verificada para o espaçamento de entrelinhas de $0,70 \mathrm{~m}$, que não sofreu interferência das épocas de semeaduras na sua taxa de elongação do colmo, tendo valores médios de $0,26 \mathrm{~cm}\left({ }^{\circ} \mathrm{C} \mathrm{dia}^{-1}\right)$ (Tabela 3$)$. A semeadura realizada no mês de dezembro apresentou diferença significativa entre os espaçamentos de entrelinhas testados, sendo que a taxa de elongação do colmo foi menor no espaçamento 0,50 m em comparação ao de $0,70 \mathrm{~m}$ (Tabela 3). A taxa de elongação do colmo tende a influenciar a taxa de alongamento foliar e a taxa de surgimento de 
folha. De acordo com Leonel e al. (2009), próximo ao subperíodo reprodutivo, há maior alocação de fotoassimilados e seus derivados para a produção de colmos em detrimento desses compostos para a produção de folhas.

A interação entre espaçamento entrelinhas e épocas de semeaduras não foi significativa para número de folhas acumulados e taxa de alongamento de folhas (Tabela 1). O espaçamento entrelinhas não diferiu entre si para o número de folhas acumuladas, sendo valor médio de 21 folhas (Tabela 3). A semeadura no mês de outubro promoveu um maior acúmulo de folhas no colmo. O número de folhas acumuladas no colmo e o alongamento da lâmina foliar são características importantes na determinação da área foliar a ser atingida pela planta, pois sabe-se que o crescimento e a produtividade das plantas são promovidos pela fotossíntese. Em geral, a área foliar é proporcional à fotossíntese realizada pela planta, logo, a produtividade das plantas depende da interceptação da luz e, consequentemente, da área foliar. O espaçamento entrelinhas e as épocas de semeaduras não diferiram entre si $(p>0,05)$ para a taxa de alongamento foliar (Tabela 3). As épocas de semeaduras e os espaçamentos entrelinhas avaliados não interferiram no alongamento foliar. Portanto, essa variável pode estar atrelada a características genotípicas e não às temperaturas do ar ao longo do ciclo (emergência até folha bandeira) nem ao manejo cultural.

Tabela 3 - Taxa de elongamento de colmo (TEC); filocrono (FIL); taxa de surgimento de folhas (TSF); número de folhas acumuladas (NFA) e taxa de alongamento de folhas (TAF) de sorgo sacarino submetido a diferentes espaçamentos de entrelinhas e épocas de semeaduras.

\begin{tabular}{|c|c|c|c|c|}
\hline \multirow{2}{*}{ Tratamentos } & Outubro & Novembro & Dezembro & Média \\
\hline & \multicolumn{4}{|c|}{ Taxa de elongamento do colmo $\mathrm{cm}\left({ }^{\circ} \mathrm{C} \mathrm{dia}\right)^{-1}$} \\
\hline Espaçamento 0,5 & $29,00 \mathrm{Aa}^{*}$ & $24,12 \mathrm{Ab}$ & $20,46 \mathrm{Bb}$ & -- \\
\hline Espaçamento 0,7 & $26,46 \mathrm{Aa}$ & $25,83 \mathrm{Aa}$ & $26,00 \mathrm{Aa}$ & -- \\
\hline \multirow[t]{2}{*}{$\mathrm{CV}(\%)$} & & 22,43 & & \\
\hline & \multicolumn{4}{|c|}{ Filocrono $\left({ }^{\circ} \mathrm{C}\right.$ dia folha $\left.{ }^{-1}\right)$} \\
\hline Espaçamento 0,5 & $50,23 \mathrm{Ab}^{*}$ & $63,04 \mathrm{Aa}$ & $46,76 \mathrm{Ab}$ & -- \\
\hline Espaçamento 0,7 & $51,03 \mathrm{Aab}$ & $53,59 \mathrm{Ba}$ & $47,75 \mathrm{Ab}$ & -- \\
\hline \multirow[t]{2}{*}{$\mathrm{CV}(\%)$} & & 12,52 & & \\
\hline & \multicolumn{4}{|c|}{ Taxa de surgimento de folhas folhas $\left({ }^{\circ} \mathrm{C} \mathrm{dia}\right)^{-1}$} \\
\hline Espaçamento 0,5 & $0,0221 \mathrm{Ab}^{*}$ & $0,0182 \mathrm{Bc}$ & $0,0240 \mathrm{Aa}$ & \\
\hline Espaçamento 0,7 & $0,0223 \mathrm{Aa}$ & $0,0203 \mathrm{Ab}$ & $0,0237 \mathrm{Aa}$ & \\
\hline \multirow[t]{2}{*}{$\mathrm{CV}(\%)$} & & 10,77 & & \\
\hline & \multicolumn{4}{|c|}{ Número de folhas acumuladas } \\
\hline Espaçamento 0,5 & 21,87 & 20,12 & 21,37 & $21,12 \mathrm{~A}^{*}$ \\
\hline Espaçamento 0,7 & 23,50 & 19,87 & 20,87 & $21,41 \mathrm{~A}$ \\
\hline Média & $22,68 a^{*}$ & $20,00 \mathrm{~b}$ & $21,12 \mathrm{~b}$ & \\
\hline \multirow[t]{2}{*}{$\mathrm{CV}(\%)$} & & 7,59 & & \\
\hline & \multicolumn{4}{|c|}{ Taxa de alongamento de folhas $\mathrm{mm}\left({ }^{\circ} \mathrm{C} \text { dia }\right)^{-1}$} \\
\hline Espaçamento 0,5 & 74,16 & 84,37 & 77,16 & $78,56 \mathrm{~A}^{*}$ \\
\hline Espaçamento 0,7 & 81,16 & 76,70 & 77,83 & $78,56 \mathrm{~A}$ \\
\hline Média & $77,66 a^{*}$ & $80,54 \mathrm{a}$ & $77,50 \mathrm{a}$ & \\
\hline $\mathrm{CV}(\%)$ & & 23,17 & & \\
\hline
\end{tabular}

*Médias seguidas da mesma letra maiúscula na coluna e minúscula na linha não diferem significativamente entre si pelo teste Tukey a $5 \%$ de significância. CV (\%) = coeficiente de variação em percentagem. 
Não houve interação dupla significativa entre os fatores espaçamento entrelinhas e genótipos de sorgo sacarino para todas as variáveis estudadas (Tabela 1). Sendo que os genótipos BRS 506 e Fepagro 19 não apresentaram diferença significativa entre si $(\mathrm{P}>0,05)$ para taxa de alongamento foliar, taxa de surgimento de folhas, número de folhas acumuladas, filocrono e taxa de elongamento de colmo (Tabela 4). Sendo os valores médios obtidos para essas variáveis de $78,56 \mathrm{~mm}^{\circ} \mathrm{C} \mathrm{dia}{ }^{-1} ; 0,22175$ folhas ${ }^{\circ} \mathrm{C} \mathrm{dia}^{-1} ; 21$ folhas; $52,07{ }^{\circ} \mathrm{C}$ dia folha ${ }^{-1}$ e $25,30 \mathrm{~cm}^{\circ} \mathrm{C} \mathrm{dia}{ }^{-1}$, respec- tivamente. Essa mesma resposta foi verificada quando se compararam os espaçamentos entrelinhas, sendo que eles não diferiram significativamente entre si $(\mathrm{P}>0,05)$, exceto para a variável filocrono (Tabela 4).

$\mathrm{O}$ espaçamento entrelinhas de $0,50 \mathrm{~m}$ apresentou maior filocrono, diferindo significativamente do espaçamento de $0,70 \mathrm{~m}$. A informação do filocrono é um importante parâmetro para avaliar o desenvolvimento das plantas, principalmente em relação à época de semeadura, pois, ao avaliarmos as diferentes épocas de cultivo, a planta está sujeita a influência de di-

Tabela 4 - Taxa de alongamento de folhas (TAF); taxa de surgimento de folhas (TSF); número de folhas acumuladas (NFA); filocrono (FIL) e taxa de elongamento do colmo (TEC) de genótipos de sorgo sacarino submetidos a diferentes espaçamentos entrelinhas.

\begin{tabular}{|c|c|c|c|}
\hline \multirow[b]{2}{*}{ Tratamentos } & Espaçamento 0,5 & Espaçamento 0,70 & Média \\
\hline & \multicolumn{3}{|c|}{ Taxa de alongamento de folhas $\mathrm{mm}\left({ }^{\circ} \mathrm{C} \text { dia }\right)^{-1}$} \\
\hline BRS 506 & 77,11 & 82,58 & $79,84 \mathrm{~A}^{*}$ \\
\hline Fepagro 19 & 80,02 & 74,55 & $77,29 \mathrm{~A}$ \\
\hline Média & $78,56 \mathrm{a}^{*}$ & $78,56 \mathrm{a}$ & \\
\hline \multirow[t]{2}{*}{$\mathrm{CV}(\%)$} & & 23,17 & \\
\hline & \multicolumn{3}{|c|}{ Taxa de surgimento de folhas folhas $\left({ }^{\circ} \mathrm{C} \text { dia }\right)^{-1}$} \\
\hline BRS 506 & 0,0213 & 0,0223 & $0,0218 \mathrm{~A}^{*}$ \\
\hline Fepagro 19 & 0,0216 & 0,0219 & $0,0217 \mathrm{~A}$ \\
\hline Média & $0,0214 \mathrm{a}^{*}$ & $0,0220 \mathrm{a}$ & \\
\hline \multirow[t]{2}{*}{ CV $(\%)$} & & 10,77 & \\
\hline & \multicolumn{3}{|c|}{ Número de folhas acumuladas } \\
\hline BRS 506 & 21,00 & 21,00 & $21,00 \mathrm{~A}^{*}$ \\
\hline Fepagro 19 & 21,00 & 22,00 & $21,50 \mathrm{~A}$ \\
\hline Média & $21,00 \mathrm{a}^{*}$ & $21,50 \mathrm{a}$ & \\
\hline \multirow[t]{2}{*}{$\mathrm{CV}(\%)$} & & 7,59 & \\
\hline & \multicolumn{3}{|c|}{ Filocrono ${ }^{\circ} \mathrm{C}$ dia folha ${ }^{-1}$} \\
\hline BRS 506 & 54,38 & 50,20 & $52,29 \mathrm{~A}^{*}$ \\
\hline Fepagro 19 & 52,32 & 51,38 & $51,85 \mathrm{~A}$ \\
\hline Média & $53,35 \mathrm{a}^{*}$ & $50,79 \mathrm{~b}$ & \\
\hline \multirow[t]{2}{*}{ CV $(\%)$} & & 12,52 & \\
\hline & \multicolumn{3}{|c|}{ Taxa de elongamento do colmo $\mathrm{cm}\left({ }^{\circ} \mathrm{C} \text { dia }\right)^{-1}$} \\
\hline BRS 506 & 25,25 & 26,30 & $25,77 \mathrm{~A}^{*}$ \\
\hline Fepagro 19 & 23,80 & 25,88 & $24,84 \mathrm{~A}$ \\
\hline Média & $24,52 \mathrm{a}^{*}$ & $26,09 \mathrm{a}$ & \\
\hline CV $(\%)$ & & 22,43 & \\
\hline
\end{tabular}


versos fatores, como temperatura, fotoperíodo, quantidade de $\mathrm{CO}_{2}$, tamanho da semente e profundidade de semeadura (Kim et al., 2007). Quanto maior o filocrono, menor é a velocidade de emissão de folhas, ou seja, mais demorada é a formação de uma folha. Além disso, esta variável está associada diretamente à taxa de surgimento de folhas no colmo.

Silva et al. (2012), avaliando a soma térmica e o filocrono de progenitores de sorgo híbrido, encontraram valores de filocrono de $283^{\circ} \mathrm{C} \mathrm{dia}^{-1}$ para o ano de 2011 e $203{ }^{\circ} \mathrm{C}$ dia $^{-1}$ para o ano de 2012 , mas eles foram avaliados em períodos de cerca de 12 dias em uma única época de semeadura para cada ano, diferente deste estudo, que avaliou semanalmente em várias épocas de semeadura, fatos que podem explicar as diferenças. Outro fato relevante, que deve ser considerado, é que a temperatura base inferior $(\mathrm{Tb})$ adotada pelos autores $\left(\mathrm{Tb}=7^{\circ} \mathrm{C}\right)$ é diferente da deste estudo (BRS 506 $=11,8{ }^{\circ} \mathrm{C}$ e Fepagro $19=11,6^{\circ} \mathrm{C}$ ), podendo, portanto, interferir nos resultados das variáveis morfogênicas com unidades em graus-dia.

\section{Conclusões}

As épocas de semeadura não influenciaram o número de folhas acumuladas e taxa de alongamento de folhas do genótipo BRS 506.

$\mathrm{O}$ atraso na semeadura resulta em menor número de folhas acumuladas e taxa de elongação do colmo para o genótipo Fepagro 19.

Os genótipos e o espaçamento entrelinhas não diferem entre si para todas as variáveis analisadas, exceto para o filocrono do espaçamento entrelinhas $0,70 \mathrm{~m}$, que é inferior ao outro espaçamento.

Logo, os espaçamentos entrelinhas e os genótipos estudados estão aptos para a produção na região de Santa Maria, no Rio Grande do Sul, desde que a semeadura ocorra em outubro, visto que a semeadura nesse mês apresentou os melhores resultados entre as variáveis estudadas, bem como nas interações duplas entre os fatores.

\section{Referências}

ALBUQUERQUE, C. J. B.; ROCHA, G. R. da; BRANT, R. S.; MENDES, M. C. Espaçamento reduzido para o cultivo do sorgo granífero no sistema irrigado e em sequeiro. Pesquisa Aplicada \& Agrotecnologia, Guarapuava, v. 3, n. 2, p. 7-16, 2010.

BANDEIRA, A. H.; MEDEIROS, S. L. P.; EMYGDIO, B. M.; BIONDO, J. C.; SILVA, N. G.; LEAL, L. T. Temperatura-base inferior e exigência térmica de genótipos de sorgo sacarino. Revista Brasileira de Milho e Sorgo, Sete Lagoas, v. 15, n. 2, p. 240-250, 2016.

DOI: 10.18512/1980-6477/rbms.v15n2p240-250.

FERNANDES, P. G.; MAY, A.; COELHO, F. C.; ABREU, M. C.; BERTOLINO, K. M. Influência do espaçamento e da população de plantas de sorgo sacarino em diferentes épocas semeadura. Ciência Rural, Santa Maria, v. 44, n. 6, p. 975 981, 2014. DOI: 10.1590/S0103-84782014000600004.

HANAUER, J. G.; STRECK, N. A.; LANGER, J. A.; KRÄULICH, B.; UHLMANN, L. O. Desenvolvimento e crescimento foliar e produtividade de cana-de-açúcar em cultivo de cana-planta e de cana-soca. Bioscience Journal, Uberlândia, v. 30, n. 4, p. 1077-1086, 2014.

HORST, G. L.; NELSON, C. J.; ASAY, K. H. Relationship of leaf elongation to forage yield of tall fescue genotypes.

Crop Science, Madison, v. 18, n. 5, p. 715-719, 1977. DOI: $10.2135 /$ cropsci1978.0011183X001800050005x.

KIM, S.-H.; GITZ, D. C.; SICHER, R. C.; BAKER, J. T.; TIMLIN, D. J.; REDDY, V. R. Temperature dependence of growth, development, and photosynthesis in maize under elevated $\mathrm{CO} 2$. Environmental and Experimental Botany, Elmsford, v. 61, n. 3, p. 224-236, 2007. DOI: 10.1016/j.envexpbot.2007.06.005. 
LEMAIRE, G.; AGNUSDEI, M. Leaf tissue turn-over and efficiency of herbage utilization. In: LEMAIRE, G.; HODGSON, J.; MORAES, A.; NABINGER, C.; CARVALHO, P. C. F. Grassland ecophysiology and grazing ecology. Wallingford: CAB International, 2000. p. 265-288.

LEMAIRE, G.; CHAPMAN, D. Tissue flows in grazed plant communities. In: HODGSON, J.; ILLIUS, A. W. (Ed.). The ecology and management of grazing systems. Wallingford: CAB International, 1996. p. 3-36.

LEONEL, F. P.; PEREIRA, J. C.; COSTA, M. G.; MARCO JÚNIOR, P.; LARA, L. A.; QUEIROS, A. C. de. Comportamento produtivo e características nutricionais do capim braquiária cultivado em consórcio com milho. Revista Brasileira de Zootecnia, Viçosa, MG, v. 38, n. 1, p. 177-189, 2009.

DOI: $10.1590 /$ S1516-35982009000100022.

MANUAL de adubação e calagem para os Estados do Rio Grande do Sul e de Santa Catarina. 10. ed. Porto Alegre: Sociedade Brasileira de Ciência do Solo: Comissão de Química e Fertilidade do Solo, 2016. 400 p.

MARTINI, A. P. M. Características morfogênicas da pastagem de sorgo forrageiro submetifo ao pastejo contínuo de novilhos de corte sumplementados. 2015. 58 f. Dissertação (Mestrado em Zootecnia) - Universidade Federal de Santa Maria, Santa Maria, 2015.

MARTINS, F. B.; SILVA, J. C. da; STRECK, N. A. Estimativa da temperatura base para emissão de folhas e do filocrono em duas espécies de eucalipto na fase de muda. Revista Árvore, Viçosa, MG, v. 31, n. 3, p. 373-381, 2007. DOI: $10.1590 / \mathrm{S} 0100-67622007000300002$.

McMASTER, G. S.; WILHELM, W. W. Accuracy of equation predicting the phyllochron of wheat. Crop Science, Madison, v. 35, n. 1, p. 30-36, 1995.

McMASTER, G. S.; WILHELM, W. W. Growing degreedays: one equation, two interpretations. Agricultural and Forest Meteorology, Amsterdam, v. 87, p. 291-300, 1997. DOI: 10.1016/S0168-1923(97)00027-0.
MOLINA, L. M. R. Um estudo sobre métodos estatísticos na avaliação de interação genótipo $x$ ambiente em linhagens de arroz (Oryza sativa L). 2007. 68 f. Dissertação (Mestrado em Genética e Melhoramento de Plantas) - Universidade Estadual Paulista, Jaboticabal, 2007.

MÜLLER, L. M. Produtividade, morfogênese e estimativa da temperatura base para genótipos diploides e tetraploides de azevém. 2009. 77 f. Tese (Doutorado em Agronomia) - Universidade Federal de Santa Maria, Santa Maria, 2009.

PENA, K. S.; NASCIMENTO JÚNIOR, D.; SILVA, S. C. da; EUCLIDES, V. P. B.; ZANINE, A. M. Características morfogênicas, estruturais e acúmulo de forragem do capim-tanzânia submetido a duas alturas e três intervalos de corte. Revista Brasileira de Zootecnia, Viçosa, MG, v. 38, n. 11, p. 2127-2136, 2009.

DOI: $10.1590 /$ S1516-35982009001100009.

ROSA, H. T.; WALTER, L. C.; STRECK, N. A.; ALBERTO, C. M. Métodos de soma térmica e datas de semeadura na determinação de filocrono de cultivares de trigo. Pesquisa Agropecuária Brasileira, Brasília, DF, v. 44, n. 11, p. 1374-1382, 2009.

DOI: 10.1590/S0100-204X2009001100002.

SALES, E. C. J. de; REIS, S. T.; ROCHA JÚNIOR, V. R.; MONÇÃO, F. P.; MATOS, V. M.; PEREIRA, D. A.; AGUIAR, A. C. R. de; ANTUNES, A. P. S. Características morfogênicas e estruturais da Brachiaria brizantha cv. Marandu submetida a diferentes doses de nitrogênio e alturas de resíduos. Semina: Ciências Agrárias, Londrina, v. 35, n. 5, p. 2673-2684, 2014.

DOI: $10.5433 / 1679-0359.2014 \mathrm{v} 35 \mathrm{n} 5 \mathrm{p} 2673$.

SANTOS, R. J. Caracterização morfogênica de acessos de azevém (Lolium multiflorum Lam.). In: REUNIÃO DO GRUPO TÉCNICO EM FORRAGEIRAS DO CONE SUL - ZONA CAMPOS, 20., 2004, Salto. Anais. Montevideo: Faculdade de Agronomia, 2004. p. 8-9.

SCHNEIDER, F. M.; BURIOL, G. A.; HELDWEIN, A. B. Temperatura base e soma térmica do subperíodo semeadura 
emergência das cultivares de soja. Ciência Rural, Santa Maria, v. 17, n. 4, p. 229-308, 1987.

SILVA, D. G. da; COELHO, R. R.; RODRIGUES, J. A. S.; FARIA, L. A. L. Determinação da soma térmica e filocrono de progenitores de sorgo híbrido. Sete Lagoas: Embrapa Milho e Sorgo, 2012. 28 p. (Embrapa Milho e Sorgo. Boletim de Pesquisa e Desenvolvimento, 55).

SILVA, F. A. S.;AZEVEDO, C.A. V. The Assistant Software version 7.7 and its use in the analysis of experimental data. African Journal Agricultural Research, v. 11, n. 39, p. 3733-3740, 2016.

DOI: 10.5897/AJAR2016.11522.

STRECK, N. A.; BOSCO, L. C.; MICHELON, S.; WALTER, L. C.; MARCOLIN, E. Duração do ciclo de desenvolvimento de cultivares de arroz em função da emissão de folhas no colmo principal. Ciência Rural, Santa Maria, v. 36, n. 4, p. 1086-1093, 2006.

DOI: $10.1590 / \mathrm{S} 0103-84782006000400007$.

TOWNSEND, C. R. Características produtivas de gramíneas nativas do gênero Paspalum, em resposta à disponibilidade de nitrogênio. 2008. 267 f. Tese (Doutorado em Zootecnia) - Universidade Federal do Rio Grande do Sul, Porto Alegre, 2008.

VILLA NOVA, N. A.; BARIONI, L. G.; PEDREIRA, C. G. S.; PEREIRA, A. R. Modelo para a previsão da produtividade do capim elefante em função de temperatura do ar, fotoperíodo e frequência de desfolha. Revista Brasileira de Agrometeorologia, Santa Maria, v. 7, n. 1, p. 75-79, 1999. 